\title{
PRODUTIVIDADE DE GRÃOS E PARÂMETROS FISIOLÓGICOS DE SORGO GRANÍFERO SOB DEFICIÊNCIA HÍDRICA E IRRIGAÇÃO PLENA
}

\author{
MAURÍCIO CASTELO BRANCO SANTANA ${ }^{1}$, EDSON ALVES BASTOS ${ }^{1}$, MILTON JOSÉ CARDOSOㄹ, \\ ADERSON SOARES DE ANDRADE JÚNIOR ${ }^{1}$, FLÁVIO DESSAUNE TARDIN ${ }^{2}$ \\ e CÍCERO BESERRA DE MENEZES ${ }^{2}$
}

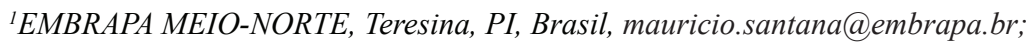

edson.bastos@embrapa.br; milton.cardoso@embrapa.br; aderson.andrade@embrapa.br

${ }^{2}$ EMBRAPA MILHO E SORGO, Sete Lagoas, MG, Brasil,flavio.tardin@embrapa.br;cicero.menezes@embrapa.br

Revista Brasileira de Milho e Sorgo, v.16, n.3, p. 361-372, 2017

\begin{abstract}
RESUMO - O presente trabalho objetivou avaliar híbridos de sorgo granífero em condições com (CDH) e sem restrição hídrica (SDH) em Teresina-PI, buscando identificar híbridos mais tolerantes ao déficit hídrico. Foram avaliados doze híbridos comerciais (DKB 599, BRS 330, AS 4610, BRS 380, BRS 309, AG 1040, BRS 310, DKB 551, 1 G 282, 50 A 50, BRS 305 e BRS 373), utilizando-se delineamento de blocos ao acaso, com quatro repetições, entre os meses de setembro e dezembro de 2012. Os tratamentos foram dispostos em esquema fatorial 2 x 12 (regimes x híbridos). $\mathrm{O}$ manejo de irrigação baseou-se na evapotranspiração da cultura. Foram determinados o índice de área foliar (IAF), o teor relativo de clorofila na folha (TCF), a eficiência de uso da água (EUA) e a produtividade de grãos. O cultivo de sorgo granífero CDH apresentou redução de 38,1\% e 36,4\% no IAF, nas leituras aos 63 e 98 dias após a semeadura, respectivamente; $9,3 \%$ no TCF e 33,1\% na produtividade de grãos em relação ao sorgo sob SDH. Em média, a EUA na condição de déficit hídrico foi superior em 7,13\%. Os híbridos BRS 305 e 1G 282 foram os mais produtivos na condição de restrição hídrico, mostrando-se também responsivos à melhoria do ambiente.
\end{abstract}

Palavras-chave: Sorghum bicolor, tolerância a seca, área foliar, teor de clorofila.

\section{GRAIN PRODUCTION AND PHYSIOLOGICAL PARAMETERS OF GRAIN SORGHUM UNDER WATER DEFICIENCY AND FULL IRRIGATION}

\begin{abstract}
Twelve commercial sorghum hybrids were evaluated under two water regimes: water deficit (WD) and full irrigation (FI), at Embrapa Meio-Norte, in Teresina, State of Piauí, Brazil, from September to December 2012. The hybrids DKB 599, BRS 330, AS 4610, BRS 380, BRS 309, AG 1040, BRS 310, DKB 551, 1 G 282, 50 A 50, BRS 305 e BRS 373 were evaluated using complete randomized blocks with four replications. The irrigation management was based on crop evapotranspiration. The irrigation applied summed to the rainfall amounted $484 \mathrm{~mm}$ and $302 \mathrm{~mm}$ for FI and WD environments, respectively. The leaf area index (LAI), the relative chlorophyll content in the leaf (RCC), water use efficiency (WUE) and grain yield were determined. The sorghum under water deficit decreased by $38.1 \%$ and $36.4 \%$ in the LAI, respectively, in the readings at 63 and 98 days after sowing; $9.3 \%$ in the RCC and $33.1 \%$ in grain yield compared to sorghum under full irrigation. The WUE under water deficit was in average $7.13 \%$ higher than under full irrigation (FI). The hybrids BRS 305 and 1G 282 showed phenotypic characteristics of drought tolerance and responsiveness to irrigation for grain production.
\end{abstract}

Keywords: Sorghum bicolor, drought tolerance, leaf area, chlorophyll content. 
O desenvolvimento de cultivares tolerantes à seca para culturas de importância econômica é um grande desafio para a pesquisa e de grande importância para a sociedade, uma vez que essas cultivares podem viabilizar o cultivo agrícola em regiões de escassez de água, como o semiárido ou em lugares onde há uma má distribuição das chuvas, aumentando, dessa forma, a produção de grãos e melhorando a qualidade de vida nesses locais.

A cultura do sorgo tem sido uma excelente opção para produção de grãos e forragem em todas as situações em que a deficiência hídrica e as condições de baixa fertilidade dos solos oferecem maiores riscos para outras culturas, notadamente para o milho. A tolerância à seca é a principal característica que faz do sorgo uma das mais importantes culturas em regiões áridas e semiáridas (Magalhães et al., 2012; Reddy, 2017). Mas o déficit hídrico continua sendo um importante fator de redução da produção mundial de sorgo.

Alguns trabalhos no Brasil têm sido conduzidos com o propósito de selecionar cultivares de sorgo para tolerância à seca (Tardin et al., 2013; Menezes et al., 2014, 2015). Menezes et al. (2014) avaliaram 25 genótipos de sorgo sob deficiência hídrica em pós-florescimento e sob irrigação normal. Foram realizados três experimentos em Nova Porteirinha-MG e um em Teresina-PI. Nos ambientes com restrição hídrica a irrigação foi cortada na fase de emborrachamento das plantas, aproximadamente aos 45 dias após semeadura. Os resultados evidenciaram que a produtividade de grãos das linhagens de sorgo sob deficiência hídrica foi $43 \%$ inferior aos ensaios sob irrigação plena. Menezes et al. (2015) avaliaram diversas linhagens de sorgo para tolerância à seca em pós-florescimento. Os experimentos foram conduzidos durante três anos consecutivos (2006, 2007 e 2008) em Nova
Porteirinha-MG e os resultados indicaram as linhagens 9929020, CMSXS 230 B e N95B como as mais tolerantes à seca, podendo ser usadas em programas de melhoramento buscando híbridos mais tolerantes.

Numerosas características da planta contribuem para tolerância ao déficit hídrico em sorgo, o que justifica aumentar esforços nos programas de melhoramento para identificá-las ou combiná-las. O índice de área foliar (IAF) é um parâmetro biométrico que pode auxiliar na identificação de genótipos com tolerância à seca, uma vez que o déficit hídrico limita o crescimento das folhas (Magalhães \& Durães, 2003). Peiter e Carlesso (1996) avaliaram a cultivar Agroceres 3001 em quatro regimes hídricos: (i) bem irrigado (irrigações aplicadas para manter a fração de água disponível superior a 0,95 no período de 33 a 104 dias após a emergência - DAE); (ii) déficit terminal (irrigações suspensas aos 33 DAE até o final do ciclo da cultura); (iii) déficit hídrico aplicado antes da antese (irrigações suspensas no período de 33 a 67 DAE); e (iv) déficit hídrico aplicado após a antese (irrigações suspensas no período de 51 a 83 DAE). Os autores encontraram valores de IAF de 4,6 e de 5,4 para as condições com e sem déficit hídrico, respectivamente, demonstrando uma redução de 14,8\% no valor do índice para condição de estresse.

O teor de clorofila na folha, a eficiência do uso de água e a produtividade de grãos são outros parâmetros que podem ser utilizados para auxiliar na identificação de materiais tolerantes ao déficit hídrico (Schaffert et al., 2011; Bacelar et al., 2012). Segundo Kerbauy (2008), o crescimento e a produtividade das plantas são promovidos pela fotossíntese, e a produtividade depende da interceptação da luz e, consequentemente, da área foliar. Por sua vez, em geral, a fotossíntese é proporcional à área foliar (Taiz \& Zeiger, 2006). Sendo assim, considera-se valiosa a 
determinação do teor de clorofila na folha como um dos parâmetros para avaliar os efeitos do déficit hídrico em sorgo granífero e outras espécies.

O aumento da eficiência do uso da água (EUA) pode ser alcançado através de diferentes estratégias. Uma dessas é a utilização de genótipos com tolerância à deficiência hídrica (Zwart \& Bastiaanssen, 2004), mas uma maior EUA das plantas não garante por si só maior adaptação à seca (Pimentel, 1998). Apesar de ser considerada uma cultura tolerante à seca, observa-se que algumas cultivares de sorgo, quando submetidas à condição hídrica satisfatória, apresentam elevadas produtividades de grãos, acima de sete toneladas (Santos et al., 2005). O interessante é se buscar cultivares tolerantes à seca, mas que apresentem elevado rendimento produtivo sob condições adequadas de cultivo. Dessa forma, essa cultivar apresentaria um bom desempenho, tanto para regime de chuvas acima ou abaixo da média.

O objetivo do presente trabalho foi avaliar o índice de área foliar, o teor de clorofila na folha, a eficiência do uso de água e a produtividade de grãos de doze híbridos comerciais de sorgo granífero submetidos às condições de irrigação plena e de deficiência hídrica, buscando identificar aqueles mais tolerantes ao déficit hídrico em pós-florescimento.

\section{Material e Métodos}

O experimento foi instalado no campo experimental da Embrapa Meio-Norte, localizado em Teresina-PI $\left(05^{\circ} 05^{\prime} \mathrm{S} ; 42^{\circ} 48^{\prime} \mathrm{W}\right.$ e $\left.74,4 \mathrm{~m}\right)$, no período de setembro a dezembro de 2012. O clima do município é do tipo Aw (clima tropical de estações úmida e seca), segundo a classificação de Köppen. O clima do município é do tipo Aw (clima tropical de estações úmida e seca), segundo a classificação de Köppen. As médias anuais de temperatura do ar, umidade relativa do ar, e precipitação pluviométrica são $28,2{ }^{\circ} \mathrm{C}$, $69,7 \%$, e 1.346,4 mm; respectivamente, concentrando a maioria das chuvas de janeiro a abril (Bastos \& Andrade Júnior, 2012). Teresina é local adequado para ensaios de campo para tolerância ao estresse hídrico, por possuir época seca bem definida, entre os meses de maio e novembro, favorecendo que o controle de água durante a condução do experimento seja realizado apenas pela irrigação. Na Figura 1, são apresentadas as temperaturas mínimas, médias e máximas, e a precipitação pluvial durante a condução do estudo.

O solo da área experimental é um Neossolo Flúvico Eutrófico, cuja classificação textural é franco arenosa, apresentando, na camada de 0 a $0,2 \mathrm{~m}$ as seguintes características químico-física: 7,93 g. $\mathrm{kg}^{-1}$ de matéria orgânica; $68 \%$ de saturação de base; $\mathrm{pH} 5,27$; P 59,2 mg.dm ${ }^{-3} ; \mathrm{K}^{+}$0,8; $\mathrm{Ca}^{2}$ 4,7; $\mathrm{Mg}^{2}$ 1,5; $\mathrm{Na} 0,17$;

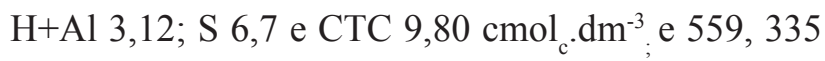
e $106 \mathrm{~g} . \mathrm{kg}^{-1}$ de areia, silte e argila, respectivamente.

$\mathrm{O}$ delineamento experimental foi o de blocos ao acaso, em esquema fatorial 2 x 12 (regimes x híbridos), com quatro repetições. Os tratamentos consistiram de doze híbridos comerciais de sorgo granífero (DKB 599, BRS 330, AS 4610, BRS 380, BRS 309, AG 1040, BRS 310, DKB 551, 1 G 282, 50 A 50, BRS 305 e BRS 373), conduzidos em dois regimes hídricos, sob irrigação plena e sob deficiência hídrica.

Cada parcela experimental foi constituída de quatro fileiras de $5 \mathrm{~m}$ de comprimento e, espaçadas de $0,5 \mathrm{~m}$, sendo considerados como área útil os $4 \mathrm{~m}$ das duas fileiras centrais (dispensando as plantas dos 0,50 $\mathrm{m}$ das cabeceiras) da unidade experimental, equivalendo a $4 \mathrm{~m}^{2}$ da parcela.

Realizou-se o preparo do solo pelo processo convencional com grade aradora e grade niveladora. As adubações foram feitas com base na análise de solo 


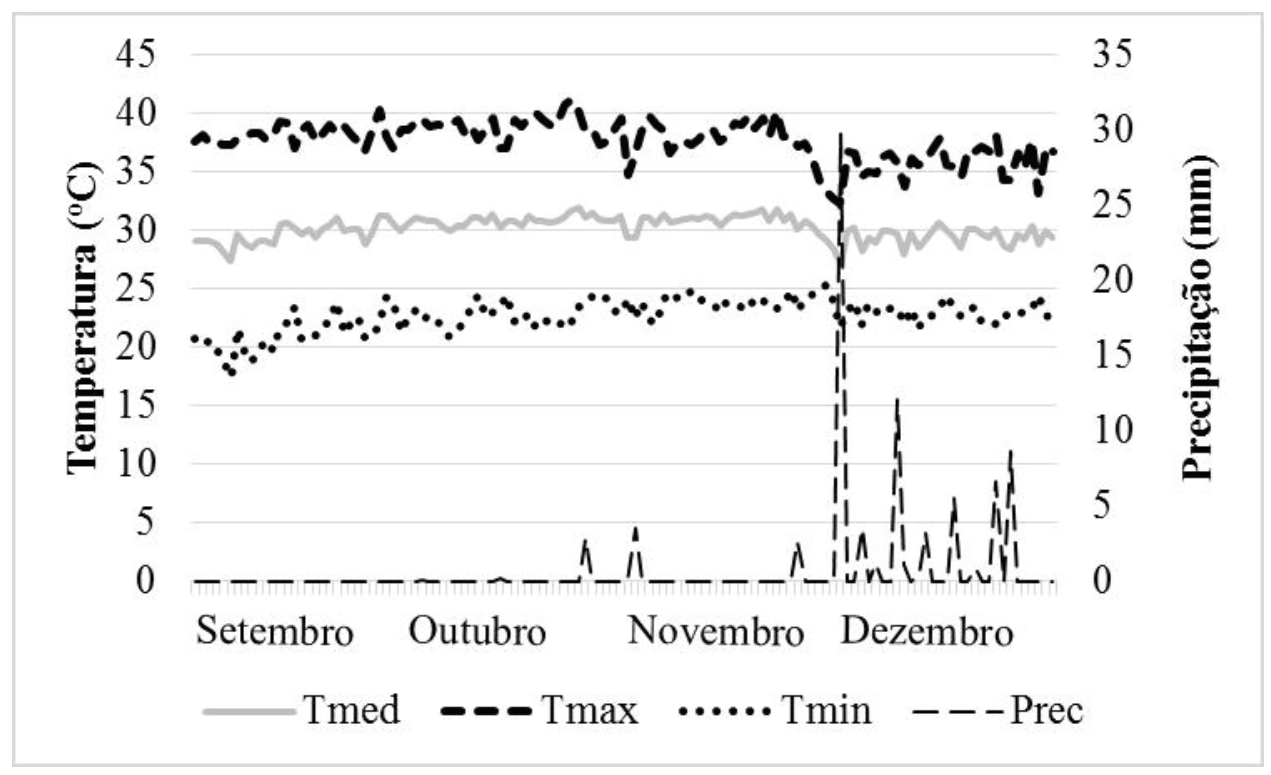

Figura 1. Valores da precipitação pluvial, temperaturas mínimas (Tmin), média (Tmed) e máxima (Tmax), ao longo do ciclo fenológico de híbridos de sorgo granífero cultivados com e sem déficit hídrico, em Teresina-PI, Safra 2012.

e nas exigências da cultura. Na adubação de fundação, foram aplicados $50 \mathrm{~kg} \mathrm{ha}^{-1} \mathrm{de} \mathrm{N}, 70 \mathrm{~kg} \mathrm{ha}^{-1} \mathrm{de}_{2} \mathrm{O}_{5}$ e 60 $\mathrm{kg} \mathrm{ha}^{-1}$ de $\mathrm{K}_{2} \mathrm{O}$ em sulcos de $0,08 \mathrm{~m}$ de profundidade. As sementes de sorgo foram semeadas manualmente em sulcos (18 sementes $/ \mathrm{m})$ à profundidade de 0,03 $\mathrm{m}$, no dia 5 de setembro de 2012. Fez-se o desbaste 15 dias após a semeadura, deixando-se 10 plantas por metro linear, totalizando um estande final de 200.000 plantas ha ${ }^{-1}$. Após 16 dias da semeadura, foi efetuada a primeira adubação de cobertura, aplicando-se $50 \mathrm{~kg}$ ha $^{-1}$ de $\mathrm{N}$ e, aos 45 dias, a segunda adubação de cobertura com $50 \mathrm{~kg} \mathrm{ha}^{-1}$ de N. Nas adubações utilizou-se como fonte de $\mathrm{N}$ o sulfato de amônio, de $\mathrm{P}_{2} \mathrm{O}_{5}$ o superfosfato triplo e de $\mathrm{K}_{2} \mathrm{O}$ o cloreto de potássio.

Foram determinadas as curvas de retenção de água no solo (Figura 2) e posteriormente ajustadas pelo modelo de Van Genuchten (1980). Considerando as camadas de $0-0,2 \mathrm{~m}$ e 0,2 - 0,4 m, os valores do conteúdo da umidade do solo referente à capacidade de campo (CC - $10 \mathrm{kPa}$ ) foram, respectivamente, de $30,24 \%$ e $27,31 \%$ e; para o ponto de murcha permanente $(\mathrm{PMP}-1.500 \mathrm{kPa})$ foram de $9 \%$ e $6,65 \%$ à base de volume.

$\mathrm{Na}$ irrigação da área foi utilizado um sistema de irrigação por aspersão convencional fixo, com os aspersores espaçados 12,0 m x 12,0 m; pressão de serviço de $250 \mathrm{kPa}$; bocais de 3,4 $\mathrm{mm}$ x 2,6 $\mathrm{mm}$ de diâmetro e com vazão de $1,6 \mathrm{~m}^{3} \mathrm{~h}^{-1}$. O manejo foi realizado com base na evapotranspiração da cultura (ETc), calculada por meio do coeficiente de cultura (Kc) proposto por Doorenbos e Kassam (1994), e a evapotranspiração de referência (ETo) foi estimada pelo método de Penman-Monteith. Os dados climáticos foram obtidos na estação agrometeorológica automática localizada a $1,5 \mathrm{~km}$ da área experimental.

O monitoramento do teor de água no solo foi obtido por meio de uma sonda de capacitância, modelo Diviner 2000, com a instalação em cada ensaio de 


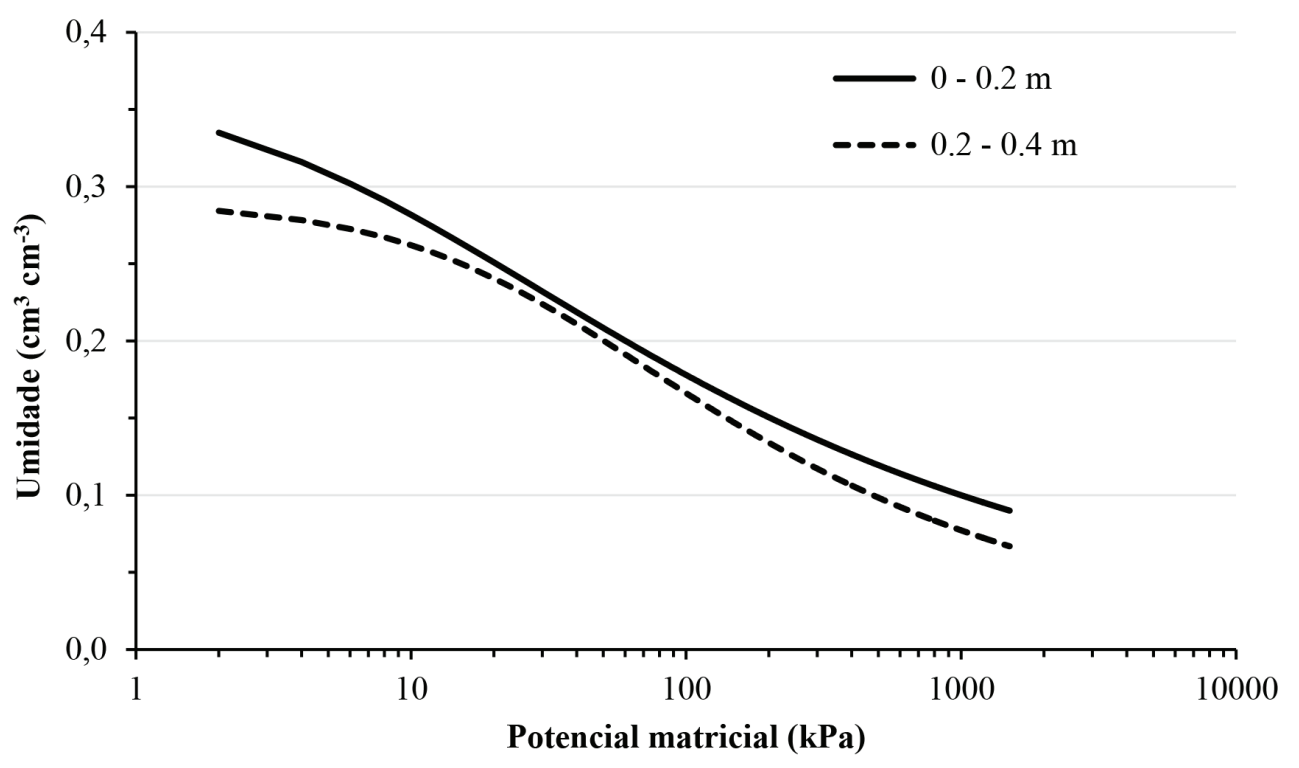

Figura 2. Curvas de retenção de água do solo da área experimental para ascamadas de 0 - 0,2 m e de 0,2 $-0,4 \mathrm{~m}$.

três tubos de acesso distribuídos aleatoriamente entre as plantas nas parcelas, em camadas de $0,10 \mathrm{~m}$ até $0,70 \mathrm{~m}$ de profundidade. No ensaio com deficiência hídrica, a irrigação foi interrompida aos 47 dias após a semeadura (DAS).

As características avaliadas foram: Índice de Área Foliar (IAF), Teor Relativo de Clorofila na Folha (TCF), Eficiência de Uso da Água (EUA) e produtividade de grãos. O índice de área foliar (IAF) foi estimado pelo produto das medidas do comprimento e maior largura de cada lâmina foliar ativa multiplicada pelo coeficiente de 0,75. A cada semana, analisou-se uma planta da área útil da parcela, dos 63 dias aos 98 dias após a semeadura (DAS). O IAF foi obtido pela razão entre a área foliar total da planta e a superfície do solo foi ocupada pela planta (Petry et al., 2007). Para realização das análises estatísticas, no intuito de obtenção de homogeneidade e normalidade dos dados para o IAF, eles foram transformados pela fórmula $\sqrt{(x+0,5)}$, onde $\mathrm{x}$ refere-se ao valor observado para IAF de cada parcela experimental.

Para as leituras do teor de clorofila na folha (TCF) usou-se um medidor portátil de clorofila da Falker, modelo clorofiLOG CFL 1030. As medidas dessa variável foram realizadas aos 68 dias após a semeadura, no terço médio da última folha completamente expandida de duas plantas previamente marcadas na área útil de cada parcela dos experimentos com e sem déficit hídrico (Falker Automação Agrícola, 2008). Foram feitas três leituras por folha a partir da base e usou-se a média delas para as análises.

A eficiência do uso da água (EUA) foi determinada pela razão entre a produtividade de grãos (umidade corrigida para $13 \%$ ) de cada híbrido e a lâmina de água utilizada para produzi-la. As lâminas de irrigação somadas à precipitação totalizaram $484 \mathrm{~mm}$ e $302 \mathrm{~mm}$ para os experimentos SDH e $\mathrm{CDH}$, respectivamente. 
Foi realizada, para cada característica, análise de variância por experimento e conjunta, ou seja, considerando os dois regimes hídricos, conforme metodologia descrita por Cruz et al. (2012). Para as características que demonstraram a ocorrência de interação entre genótipos e regimes hídrico, foi realizado o desdobramento da interação, avaliando os genótipos dentro de cada regime hídrico. Para as características, que demonstraram diferenças estatísticas significativas pelo teste $\mathrm{F}$, no intuito de verificar diferenças entre médias, foi realizado o teste de Scott-Knott, ao nível de 5\% de probabilidade, entre os híbridos, dentro de cada ambiente. Para tanto, os dados obtidos foram analisados utilizando-se os recursos computacionais do programa GENES (Cruz, 2013).

\section{Resultados e Discussão}

No período de condução do experimento foi registrada precipitação pluvial total de 63,2 mm. Porém, até os 87 dias após a semeadura, o total de precipitação foi de apenas 9,2 mm (Figura 2), não influenciando no déficit hídrico imposto à cultura. As temperaturas mínimas apresentaram uma variação de $17,4{ }^{\circ} \mathrm{C}$ a $25,2{ }^{\circ} \mathrm{C}$; as médias de $27,0{ }^{\circ} \mathrm{C}$ a $31,9{ }^{\circ} \mathrm{C}$ e as máximas entre $32,3{ }^{\circ} \mathrm{C}$ e $41,1{ }^{\circ} \mathrm{C}$ (Figura 2). Os valores de umidade relativa do ar (UR \%) variaram entre $36 \%$ e $79 \%$.

O monitoramento da umidade do solo (Figura 3 ) indica que, no experimento com déficit hídrico, os valores mínimos de umidade na camada de 0 - 0,4 m ficaram abaixo de $50 \%$ da capacidade de esgotamento hídrico do solo. Enquanto que, na condição sem déficit hídrico, a umidade foi mantida superior à capacidade de campo.

As lâminas de irrigação aplicadas acrescidas pela precipitação, ocorridas ao longo do período da semeadura à colheita, totalizaram $302 \mathrm{~mm}$ e $484 \mathrm{~mm}$ para os experimentos com déficit hídrico e sem déficit hídrico, respectivamente.

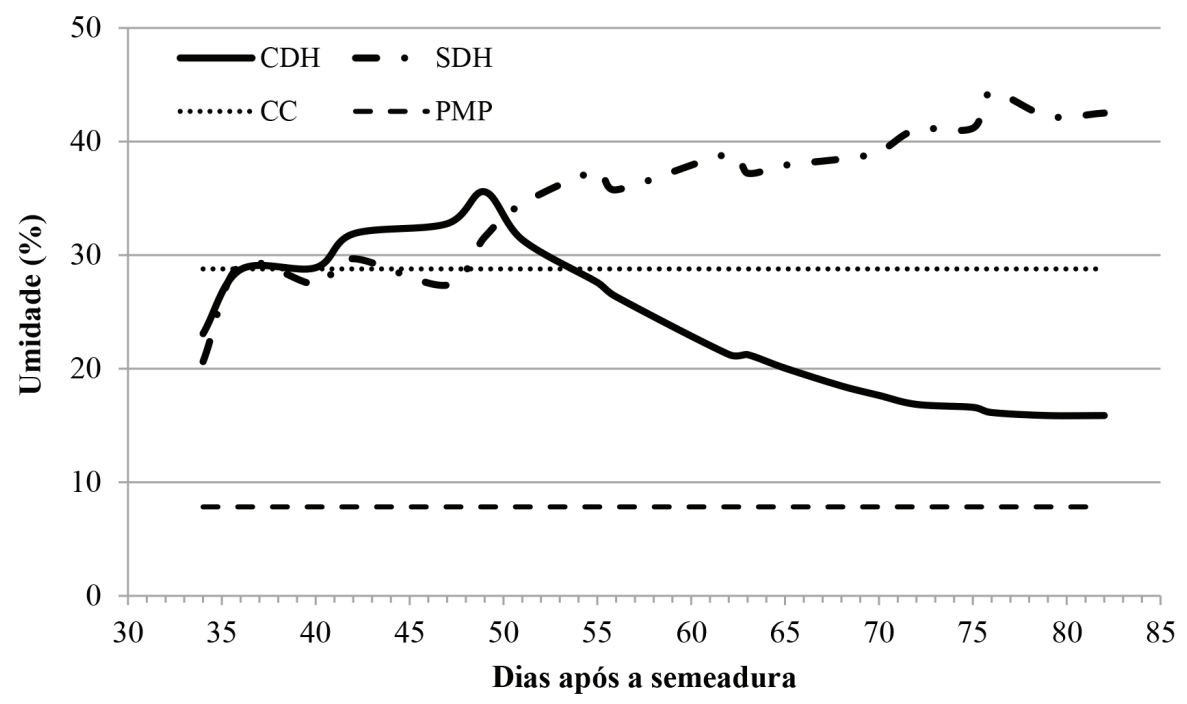

Figura 3. Variação da umidade do solo (\% em volume) até a profundidade de $0,4 \mathrm{~m}$; ao longo do ciclo fenológico de híbridos de sorgo granífero cultivados com e sem déficit hídrico, em Teresina-PI, Safra 2012. Legenda: $\mathrm{CDH}$ - experimento com déficit hídrico; SDH - experimento sem déficit hídrico; CC - capacidade de campo; PMP - ponto de murcha permanente. 
A análise de variância conjunta dos dados revelou efeito significativo a $1 \%$ de significância para a fonte de variação híbridos, mostrando o comportamento diferenciado entre os híbridos avaliados (Tabela 1). A interação híbridos x regimes também foi significativa, com exceção da característica eficiência no uso da água, mostrando um ordenamento diferente dos híbridos dentro de cada ambiente para estas características. O coeficiente de variação foi baixo para TCL e intermediário para as outras características, mesmo assim estão dentro dos limites encontrados na literatura para estudos de tolerância à seca em campo.

Para a característica produtividade de grãos, as médias variaram de $2.515,6$ a $5.842,6 \mathrm{~kg} \mathrm{ha}^{-1} \mathrm{e}$ de $3.036,4$ a 7.688,5 $\mathrm{kg} \mathrm{ha}^{-1}$; nos regimes hídricos com e sem déficit hídrico, respectivamente (Tabela 2). Comparando os dois regimes, ocorreu uma redução de $33,1 \%$ na média geral da produtividade de grãos sob condição de déficit hídrico em relação à irrigação plena, demonstrando que o sorgo mesmo sendo tolerante ainda sofre redução de produtividade quando em condições de estresse hídrico. Batista (2016), ao avaliar a média da produtividade de grãos em ensaios com e sem estresse hídrico em Nova Porteirinha-MG e Teresina-PI, observou que o estresse hídrico reduziu a produtividade de grãos em 35\% e 65\% nos anos de 2014 e 2015, respectivamente. Esses resultados mostram que o estresse hídrico se manifesta em diferentes intensidades nos locais de condução e também no mesmo local em anos diferentes, demonstrando a importância de outros fatores edafoclimáticos que estão atrelados ao estresse hídrico e da condução do experimento em diferentes anos e localidades. Reduções na produtividade de grãos ocasionadas pelo estresse hídrico em pós-florescimento também foram observadas por Menezes et al. (2015), que encontraram reduções de 39\% em linhagens de sorgo granífero, e por Tardin et al. (2013), que obtiveram reduções de 54\% em híbridos de sorgo granífero.

Os híbridos BRS 305 e o $1 \mathrm{G} 282$ apresentaram as maiores produtividades de grãos nas duas condições (Tabela 2). Estes resultados indicam que eles apresentam maior capacidade de tolerância à seca e são responsivos à irrigação, características altamente desejadas para híbridos de sorgo. Novos estudos são necessários para caracterizar melhor esses híbridos e entender os processos fisiológicos que os fazem mais

Tabela 1. Análise de variância conjunta para produtividade de grãos (Prod), índice de área foliar aos 63 dias e 98 dias após semeadura, teor de clorofila da folha (TCF) e eficiência no uso de água, avaliados em 12 híbridos de sorgo granífero cultivados com e sem déficit hídrico, em Teresina-PI, Safra 2012.

\begin{tabular}{ccccccc}
\hline & & \multicolumn{5}{c}{ Quadrados Médios } \\
\cline { 3 - 6 } FV & GL & $\begin{array}{c}\text { Prod } \\
\left(\mathrm{kg} \mathrm{ha}^{-1}\right)\end{array}$ & $\begin{array}{c}\text { IAF } \\
63 \text { dias }\end{array}$ & $\begin{array}{c}\text { IAF } \\
98 \text { dias }\end{array}$ & TCL & $\begin{array}{c}\text { EUA } \\
\left(\mathrm{kg} \mathrm{ha}^{-1} \mathrm{~mm}^{-1}\right)\end{array}$ \\
\hline Bloco/regimes & 6 & 579392 & 10,62 & 9.23 & 18.93 & 27.762 \\
Híbridos (H) & 11 & $9180329^{* *}$ & $28,95^{* *}$ & $30.07^{* *}$ & $74.99 * *$ & $58.8008^{* *}$ \\
Regimes (R) & 1 & $75198857^{* *}$ & $131,39^{*}$ & $89.28^{*}$ & $518.09^{* *}$ & $15.5485^{\mathrm{ns}}$ \\
H x R & 11 & $2489510^{* *}$ & $3,94^{\mathrm{ns}}$ & $3,34^{\mathrm{ns}}$ & $13.71^{\mathrm{ns}}$ & $13.1735^{* *}$ \\
Resíduo & 66 & 547026 & 5.19 & 4.14 & 17.09 & 39.785 \\
\hline CV (\%) & & 16.52 & 21,29 & 21,52 & 8,74 & 17,4 \\
\hline
\end{tabular}

ns $, *, * *$ não significativo, significativo a $5 \%$ e a $1 \%$ de probabilidade, pelo teste $\mathrm{F}$ 
Tabela 2. Médias para produtividade de grãos, avaliadas em 12 híbridos de sorgo granífero cultivados com (CDH) e sem (SDH) déficit hídrico, em Teresina-PI, Safra 2012.

\begin{tabular}{|c|c|c|}
\hline \multirow{2}{*}{ Híbridos } & \multicolumn{2}{|c|}{ Produtividade grãos $\left(\mathrm{kg} \mathrm{ha}^{-1}\right)$} \\
\hline & $\mathrm{CDH}$ & $\mathrm{SDH}$ \\
\hline DKB 599 & 3066,9 с B & 6060,1 b A \\
\hline BRS 330 & 2515,6 c A & $3036,4 \mathrm{~d} \mathrm{~A}$ \\
\hline AS 4610 & 3746,6 с A & 4259,2 c A \\
\hline BRS 380 & 3010,4 c A & $3606,1 \mathrm{~d} \mathrm{~A}$ \\
\hline BRS 309 & 3602,4 c B & 4995,0 c A \\
\hline AG 1040 & 3362,6 c B & 6351,1 b A \\
\hline BRS 310 & 3828,0 с B & 4727,8 с A \\
\hline DKB 551 & 2893,2 c A & 5576,6 b A \\
\hline $1 \mathrm{G} 282$ & 4767,2 b A & 7688,5 a A \\
\hline 50 A 50 & 3011,4 c A & 6318,3 b A \\
\hline BRS 305 & 5842,6 a A & 7329,4 a A \\
\hline BRS 373 & 3451,8 с B & 4391,7 с A \\
\hline Média & 3591,6 & 5361,7 \\
\hline $\mathrm{CV}(\%)$ & & \\
\hline
\end{tabular}

Médias seguidas de mesma letra maiúscula na linha e minúscula na coluna não diferem estatisticamente pelo teste de Scott-Knott, ao nível de 5\% de probabilidade.

tolerantes ao estresse hídrico. Os híbridos com maiores reduções na produtividade de grãos foram $\mathrm{DKB}$ 599, AG 1040 e DKB 551, com reduções acima de $47 \%$ quando comparados os dois regimes hídricos.

Os parâmetros índice de área foliar e teor de clorofila total na folha não apresentaram interação significativa entre híbridos e regimes hídrico (Tabela 1), por isso se fez o teste de agrupamento nas médias gerais e não dentro de cada regime hídrico, ou seja, realizou-se o teste calculando-se a média geral do híbrido sem se considerar o regime hídrico individualmente. Constatou-se a ocorrência de redução média de $38,1 \%$ na leitura feita aos 63 dias após a semeadura entre os dois regimes de disponibilidade hídrica e de $36,4 \%$ na leitura seguinte aos 98 DAS (Tabela 3 ). Resultados obtidos por Peiter e Carlesso (1996) em pesquisa com sorgo demonstraram redução do IAF sob déficit hídrico em 14,8\%. Segundo Taiz e Zeiger
(2006), a expansão foliar é um processo movido pelo turgor e extremamente sensível ao déficit hídrico. A inibição da expansão celular provoca uma lentidão da expansão foliar no início do desenvolvimento de déficits hídricos. Os maiores índices de área foliar foram obtidos para os híbridos DKB 599 e BRS 305.

Outra característica muito importante em trabalhos de sorgo para tolerância à seca é o teor de clorofila na planta. Maiores teores de clorofila sugerem senescência foliar atrasada, permitindo assim que a fotossíntese continue ativa em condição de estresse hídrico, favorecendo, dessa forma, a produção de fotoassimilados e facilitando, portanto, o enchimento dos grãos. Na avaliação do teor de clorofila total (TCF), a leitura foi realizada aos 68 dias após a semeadura (DAS), não ocorrendo interação significativa entre os regimes e os híbridos avaliados. O TCF sofreu redução média de 9,3\% na condição de déficit 
Tabela 3. Médias para índice de área foliar (IAF), avaliadas aos 63 e 98 dias após a semeadura (DAS), em 12 híbridos de sorgo granífero, cultivados com (CDH) e sem (SDH) déficit hídrico, em Teresina-PI, safra 2012.

\begin{tabular}{|c|c|c|c|c|c|c|}
\hline \multirow[t]{3}{*}{ Híbridos } & \multicolumn{6}{|c|}{ IAF } \\
\hline & \multicolumn{3}{|c|}{$63 \mathrm{DAS}$} & \multicolumn{3}{|c|}{$98 \mathrm{DAS}$} \\
\hline & $\mathrm{CDH}$ & $\mathrm{SDH}$ & Média & $\mathrm{CDH}$ & $\mathrm{SDH}$ & Média \\
\hline DKB 599 & 6,7 & 11,5 & $9,1 \mathrm{a}$ & 6,5 & 10,1 & $8,3 \mathrm{a}$ \\
\hline BRS 330 & 3,0 & 6,4 & $4,7 \mathrm{~b}$ & 2,5 & 5,9 & $4,2 \mathrm{~b}$ \\
\hline AS 4610 & 3,2 & 4,5 & $3,8 \mathrm{~b}$ & 2,7 & 3,2 & $3,0 \mathrm{c}$ \\
\hline BRS 380 & 2,1 & 4,5 & $3,3 \mathrm{~b}$ & 1,8 & 3,6 & $2,7 \mathrm{c}$ \\
\hline BRS 309 & 2,3 & 5,5 & $3,9 \mathrm{~b}$ & 1,6 & 4,9 & $3,2 \mathrm{c}$ \\
\hline AG 1040 & 5,3 & 6,4 & $5,9 \mathrm{~b}$ & 4,7 & 5,6 & $5,1 \mathrm{~b}$ \\
\hline BRS 310 & 2,8 & 6,0 & $4,4 \mathrm{~b}$ & 2,6 & 4,5 & $3,6 \mathrm{c}$ \\
\hline DKB 551 & 4,2 & 8,1 & $6,2 \mathrm{~b}$ & 3,7 & 7,3 & $5,5 \mathrm{~b}$ \\
\hline $1 \mathrm{G} 282$ & 3,1 & 5,3 & $4,2 \mathrm{~b}$ & 2,8 & 5,2 & $4,0 \mathrm{~b}$ \\
\hline 50 A 50 & 5,3 & 5,2 & $5,2 \mathrm{~b}$ & 4,5 & 4,6 & $4,5 \mathrm{~b}$ \\
\hline BRS 305 & 7,3 & 8,7 & $8,0 \mathrm{a}$ & 7,2 & 8,4 & $7,8 \mathrm{a}$ \\
\hline BRS 373 & 2,0 & 3,5 & $2,7 \mathrm{~b}$ & 1,7 & 2,3 & $2,0 \mathrm{c}$ \\
\hline Média & 3,9 & $6,3 \quad A$ & 5,1 & 3,5 & $5,5 \mathrm{~A}$ & 4,5 \\
\hline CV (\%) & & 21,29 & & & 21,52 & \\
\hline
\end{tabular}

Médias seguidas de mesma letra minúscula na coluna e maiúscula na linha não diferem estatisticamente pelo teste de Scott-Knott, ao nível de $5 \%$ de probabilidade.

hídrico em relação à condição sem déficit (Tabela 4). Batista (2016) avaliou a clorofila na planta de sorgo, em 29 híbridos de sorgo, através do índice SPAD aos 60,75 e 90 dias após semeadura. Os valores encontrados aos 60 dias foram próximos aos encontrados no presente trabalho. No ambiente com estresse, o índice foi de 53,9 e no ambiente sem estresse foi de 56,0. O autor também mostrou que aos 90 dias após semeadura, o índice SPAD apresenta elevada correlação com produtividade de grãos, encontrando valores de 27,5 e 55 nas condições com e sem estresse hídrico, respectivamente. Magalhães et al. (2010), avaliando características morfofisiológicas e de produção de seis genótipos de sorgo submetidos ao estresse hídrico em casa de vegetação, encontraram valores de índice SPAD no início do estresse variando de 53,11 a 60,08. Para Efeoğlu et al. (2009), a redução do TCF está associada à aceleração da senescência foliar cau- sada pelo déficit hídrico. Portanto, a redução no TCF pode ter impacto na produção por reduzir a eficiência fotossintética (Blum, 2005), que é diretamente relacionada com a quantidade de clorofila nas folhas.

Na Tabela 5, são mostrados os valores médios de eficiência do uso da água (EUA). Houve interação significativa entre híbrido e regime hídrico a $1 \%$ de probabilidade. Por isso, fez-se o teste de médias entre híbridos dentro de cada regime hídrico. As médias da EUA na condição de déficit hídrico ficaram entre 8,31 e $19,31 \mathrm{~kg} \mathrm{ha}^{-1} \mathrm{~mm}^{-1}$. A média geral no ambiente com déficit hídrico foi de $11,87 \mathrm{~kg} \mathrm{ha}^{-1} \mathrm{~mm}^{-1}$, superior $7,13 \%$ à média geral na condição SDH. Tanto na condição sob déficit hídrico como na irrigação plena, os híbridos BRS 305 e 1G 282 apresentaram os maiores índices de EUA. Esses dois híbridos não diferiram estatisticamente entre si na condição sem déficit hídrico. 
Tabela 4. Médias para teor de clorofila na folha (TCF), avaliadas aos 68 dias após a semeadura, em 12 híbridos de sorgo granífero cultivados com (CDH) e sem (SDH) déficit hídrico, em Teresina-PI, Safra 2012.

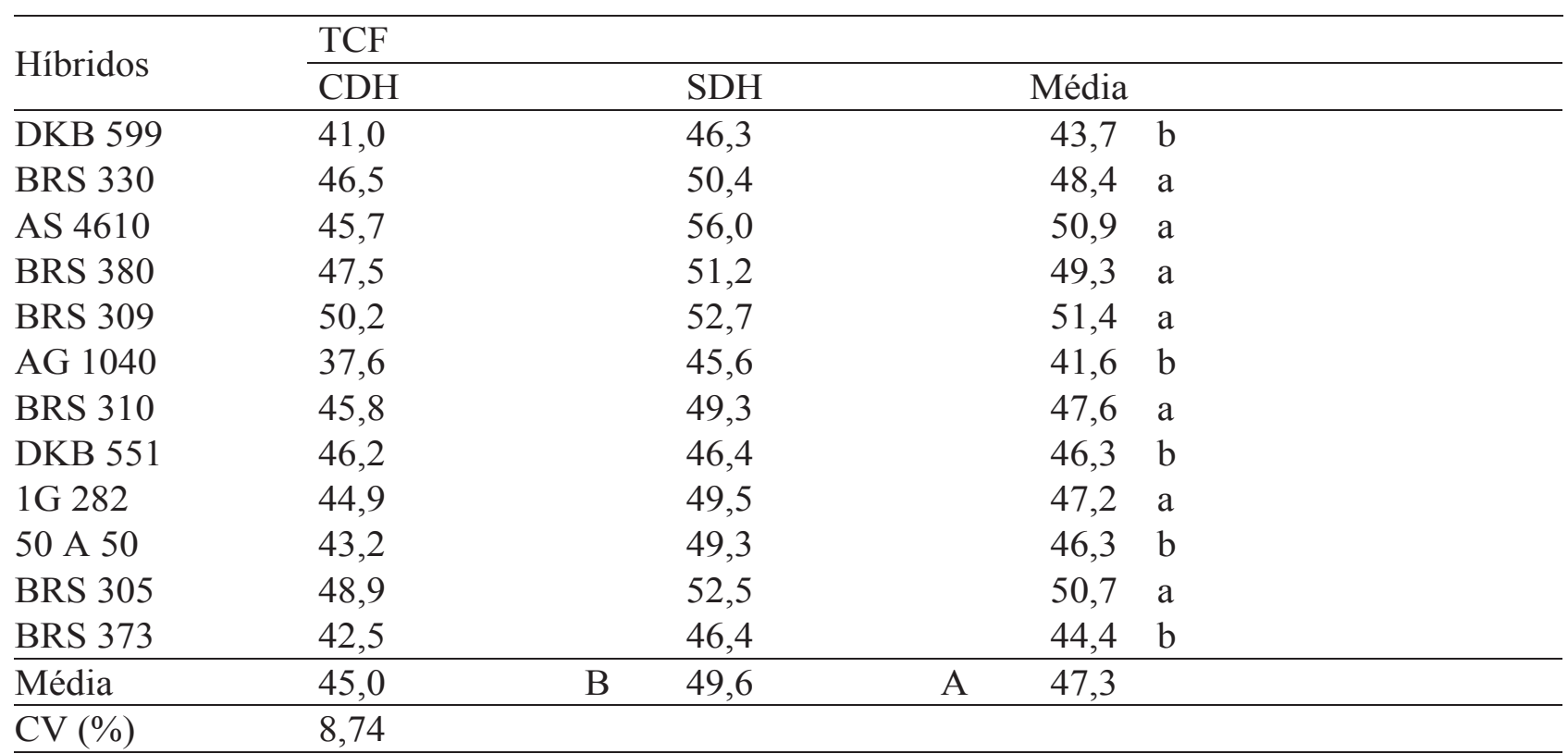

Médias seguidas de mesma letra minúscula na coluna e maiúscula na linha não diferem estatisticamente pelo teste Scott-Knott ao nível de $5 \%$ de probabilidade.

Tabela 5. Médias para eficiência do uso de água (EUA), avaliadas em 12 híbridos de sorgo granífero cultivados com (CDH) e sem (SDH) déficit hídrico, em Teresina-PI, Safra 2012.

\begin{tabular}{|c|c|c|c|c|}
\hline \multirow{2}{*}{ Híbridos } & \multicolumn{4}{|c|}{$\operatorname{EUA}\left(\mathrm{kg} \mathrm{ha}^{-1} \mathrm{~mm}^{-1}\right)$} \\
\hline & $\mathrm{CDH}$ & \multicolumn{3}{|c|}{$\mathrm{SDH}$} \\
\hline DKB 599 & 10,14 & $\mathrm{~d} A$ & 12,51 & b A \\
\hline BRS 330 & 8,31 & $\mathrm{~d} A$ & 6,27 & d A \\
\hline AS 4610 & 12,38 & c A & 8,79 & c B \\
\hline BRS 380 & 9,95 & $\mathrm{~d} A$ & 7,44 & d A \\
\hline BRS 309 & 11,90 & c A & 10,31 & c A \\
\hline AG 1040 & 11,11 & c A & 13,11 & b A \\
\hline BRS 310 & 12,65 & c A & 9,76 & c B \\
\hline DKB 551 & 9,56 & $\mathrm{~d} A$ & 11,51 & $\mathrm{~b} A$ \\
\hline 1G 282 & 15,75 & $\mathrm{~b} A$ & 15,87 & $\mathrm{aA}$ \\
\hline 50 A 50 & 9,95 & d B & 13,04 & b A \\
\hline BRS 305 & 19,31 & $\mathrm{aA}$ & 15,12 & a B \\
\hline BRS 373 & 11,41 & c A & 9,06 & c A \\
\hline Média & 11,87 & & 11,08 & \\
\hline$\overline{C V(\%)}$ & & & 17,4 & \\
\hline
\end{tabular}

Médias seguidas pela mesma letra maiúscula na linha e minúscula na coluna não diferem estatisticamente pelo teste de Scott-Knott, ao nível de $5 \%$ de probabilidade. 
Todas as características avaliadas foram afetadas pelo estresse hídrico, sendo a produtividade de grãos a que apresentou maior redução causada pelo estrese. No entanto, foi possível encontrar híbridos com produtividades acima de $4.500 \mathrm{~kg} \mathrm{ha}^{-1}$, mesmo sob condições de déficit hídrico. Estes valores mostram que a cultura do sorgo possui potencial para ser plantado em áreas com déficit hídrico ou em regiões com distribuição errática de chuvas, como o Nordeste.

\section{Conclusões}

O déficit hídrico reduz significativamente o índice de área foliar, o teor de clorofila na planta, e em especial a produtividade de grãos de sorgo.

Os híbridos de sorgo granífero BRS 305 e $1 \mathrm{G}$ 282 apresentam características de tolerância à deficiência hídrica e são responsivos à irrigação.

\section{Agradecimentos}

À Embrapa Milho e Sorgo, pela cessão das sementes, e ao Setor de Campos Experimentais da Embrapa Meio-Norte, pelo apoio imprescindível na condução dos experimentos.

\section{Referências}

BACELAR, E. L. V. A.; MOUTINHO-PEREIRA, J. M.; GONÇALVES, B. M. C.; BRITO, C. V. Q.; GOMESLARANJO, J.; FERREIRA, H. M. F.; CORREIA, C. M. Water use strategies of plants under drought conditions. In: AROCA, R. (Ed.). Plant responses to drought stress. Heidelberg: Springer-Verlag, 2012. p. 145-195.

BASTOS, E. A.; ANDRADE JÚNIOR, A. S. de. Boletim Agrometeorológico de 2011 para o município de Teresina, Piauí. Teresina: Embrapa Meio-Norte, 2012. 37 p. (Embrapa Meio-Norte. Documentos, 220).
BATISTA, P. S. Seleção fenotípica de híbridos de sorgo granífero para tolerância à seca. 2016. 95 f. Dissertação (Mestrado) - Universidade Estadual de Montes Claros, Janaúba, 2016.

BLUM, A. Drought resistance, water-use efficiency, and yield potential are they compatible, dissonant or mutually exclusive? Australian Journal of Agricultural Research, Melbourne, v. 56, n. 11, p. 1159-1168, 2005.

DOI: 10.1071/AR05069.

CRUZ, C. D. GENES: a software package for analysis in experimental statistics and quantitative genetics. Acta Scientiarum. Agronomy, Maringá, v. 35, n. 3, p. 271-276, 2013.

DOI: 10.4025/actasciagron.v35i3.21251.

CRUZ, C. D.; REGAZZI, A. J.; CARNEIRO, P. C. S. Modelos biométricos aplicados ao melhoramento genético. 4. ed. Viçosa, MG: UFV, 2012. v. 1, 514 p.

DOORENBOS, J.; KASSAM, A. H. Efeito da água no rendimento das culturas. Campina Grande: UFPB, 1994. 306 p. (Estudos FAO. Irrigação e Drenagem, 33).

EFEOĞLU, B.; EKMEKÇI, Y.; ÇIÇEK, N. Physiological responses of three maize cultivars to drought stress and recovery. South African Journal of Botany, Pietermaritzburg, v. 75, n. 1, p. 34-42, 2009.

FALKER AUTOMAÇÃO AGRÍCOLA. Manual do medidor eletrônico de teor clorofila (ClorofiLOG/ CFL 1030). Porto Alegre, 2008.

KERBAUY, G. B. Fisiologia vegetal. 2. ed. Rio de Janeiro: Guanabara Koogan, 2008. 431 p.

MAGALHÃES, P. C.; ALBUQUERQUE, P. E. P.; VIANA, J. H. M. Resposta fisiológica do sorgo ao estresse hídrico em casa de vegetação. Sete Lagoas: Embrapa Milho e Sorgo, 2012. 21 p. (Embrapa Milho e Sorgo. Boletim de Pesquisa e Desenvolvimento, 46).

MAGALHÃES, P. C.; DURÃES, F. O. M. Ecofisiologia da produção de sorgo. Sete Lagoas: Embrapa Milho e 
Sorgo, 2003. 4 p. (Embrapa Milho e Sorgo. Comunicado Técnico, 87).

MAGALHÃES, P. C.; PEREIRA, F. J.; SCHAFFERT, R. E.; ALBUQUERQUE, P. E. P. de; MAGALHÃES, J. V. Características morfofisiológicas e de produção de seis genótipos de sorgo submetidos ao estresse hídrico. Sete Lagoas: Embrapa Milho e Sorgo, 2010. 16 p. (Embrapa Milho e Sorgo. Boletim de Pesquisa e Desenvolvimento, 22).

MAGALHÃES, P. C.; SOUZA, T. C.; ALBUQUERQUE, P. E. P.; KARAM, D.; MAGALHÃES, M. M.; CANTÃO, F. R. O. Caracterização ecofisiológica de linhagens de milho submetidas a baixa disponibilidade hídrica durante o florescimento. Revista Brasileira de Milho e Sorgo, Sete Lagoas, v. 8, n. 3, p. 223-232, 2009.

DOI: 10.18512/1980-6477/rbms.v8n3p223-232.

MENEZES, C. B.; BENAVENTE, C. A. T.; TARDIN, F. D.; CARDOSO, M. J.; BASTOS, E. A.; NOGUEIRA, D. W.; PORTUGAL, A. F.; SANTOS, C. V.; SCHAFFERT, R. E. Selection indices to identify drought-tolerant grain sorghum cultivars. Genetics and Molecular Research, Ribeirão Preto, v. 13, n. 4, p. 9817-9827, 2014.

DOI: 10.4238/2014.November.27.9.

MENEZES, C. B.; RIBEIRO, A. S.; TARDIN, F. D.; CARVAlHO, A. J.; BASTOS, E. A.; CARDOSO, M. J.; PORTUGAL, A. F.; SILVA, K. J.; SANTOS, C. V.; ALMEIDA, F. H. L. Adaptabilidade e estabilidade de linhagens de sorgo em ambientes com e sem restrição hídrica. Revista Brasileira de Milho e Sorgo, Sete Lagoas, v. 14, n. 1, p. 101-115, 2015.

DOI: 10.18512/1980-6477/rbms.v14n1p101-115.

PEITER, M. X.; CARLESSO, R. Comportamento do sorgo granífero em função de diferentes frações da água disponível no solo. Ciência Rural, Santa Maria, v. 26, n. 1, p. 51-55, 1996. DOI: 10.1590/S0103-84781996000100010.

PETRY, M. T.; ZIMMERMANN, F. L.; CARLESSO, R.; MICHELON, C. J.; KUNZ, J. H. Disponibilidade de água do solo ao milho cultivado sob sistemas de semeadura direta e preparo convencional. Revista Brasileira de
Ciência do Solo, Viçosa, MG, v. 31, n. 3, p. 531-539, 2007. DOI: 10.1590/S0100-06832007000300013.

PIMENTEL, C. Metabolismo de carbono na agricultura tropical. Seropédica: Edur, 1998. 150 p.

REDDY, P. S. Sorghum, Sorghum bicolor (L.) Moench. In: PATIL, J. V. (Ed.). Millets and sorghum: biology and genetic improvement. West Sussex: Wiley Blackwell, 2017. p. 1-48.

SANTOS, F. G.; CASELA, C. R.; WAQUIL, J. M. Melhoramento do sorgo. In: BORÉM, A. Melhoramento das espécies cultivadas. 2. ed. Viçosa, MG: UFV, 2005. p. 605-812.

SCHAFFERT, R. E.; ALBUQUERQUE, P. E. P.; DUARTE, J. O.; GARCIA, J. C.; GOMIDE, R. L.; GUIMARÃES, C. T.; MAGAlhãeS, P. C.; MAGAlhãES, J. V.; QUEIROZ, V. A. V. Phenotyping sorghum for adaptation to drought. In: MONNEVEUX, P.; RIBAUT, J. M. (Ed.). Drought phenotyping in crops: from theory to practice. México, DF: CGIAR: CIMMYT, 2011. pt. 2, p. 287-299.

TAIZ, L.; ZEIGER, E. Fisiologia vegetal. 3. ed. Porto Alegre: Artmed, 2006. 722 p.

TARDIN, F. D.; ALMEIDA FILHO, J. E. de; OLIVEIRA, C. M. de; LEITE, C. E. do P.; MENEZES, C. B. de; MAGAlHÃES, P. C.; RODRIGUES, J. A. S.; SCHAFFERT, R. E. Avaliação agronômica de híbridos de sorgo granífero cultivados sob irrigação e estresse hídrico. Revista Brasileira de Milho e Sorgo, Sete Lagoas, v. 12, n. 2, p. 102-117, 2013.

DOI: 10.18512/1980-6477/rbms.v12n2p102-117.

VAN GENUCHTEN, M. T. A closed-form equation for predicting hydraulic conductivity of unsaturated soils. Soil Science Society of America Journal, Madison, v. 44, n. 5 , p. 892-898, 1980.

ZWART, S. J.; BASTIAANSSEN, W. G. M. Review of measured crop water productivity values for irrigated wheat, rice, cotton and maize. Agricultural Water Management, Amsterdam, v. 69, n. 2, p. 115-133, 2004. 